\title{
BMJ Open Retrospective cohort study of androgen deprivation therapy and the risk of diabetes in men with prostate cancer in Lithuania
}

\author{
Mingaile Drevinskaite (D) ,", Ausvydas Patasius (D) , ${ }^{1,3}$ Marius Kincius, ${ }^{4}$ \\ Vincas Urbonas, ${ }^{4}$ Giedre Smailyte (D) ${ }^{1,3}$
}

To cite: Drevinskaite M, Patasius A, Kincius M, et al. Retrospective cohort study of androgen deprivation therapy and the risk of diabetes in men with prostate cancer in Lithuania. BMJ Open 2021;11:e045797. doi:10.1136/ bmjopen-2020-045797

- Prepublication history for this paper is available online. To view these files, please visit the journal online (http://dx.doi. org/10.1136/bmjopen-2020045797).

Received 15 0ctober 2020 Accepted 14 June 2021

D) Check for updates

(c) Author(s) (or their employer(s)) 2021. Re-use permitted under CC BY-NC. No commercial re-use. See rights and permissions. Published by BMJ.

${ }^{1}$ Laboratory of Cancer Epidemiology, Nacionalinis Véžio Institutas, Vilnius, Lithuania

${ }^{2}$ Faculty of Medicine, Vilnius University, Vilnius, Lithuania ${ }^{3}$ Faculty of Medicine, Institute of Health Sciences, Vilniaus Universitetas, Vilnius, Lithuania

${ }^{4}$ Laboratory of Clinical Oncology, Nacionalinis Vèžio Institutas, Vilnius, Lithuania

Correspondence to

Mingaile Drevinskaite;

mingaile.drevinskaite@nvi.It

\section{ABSTRACT}

Objectives To examine the risk of type 2 diabetes in patients with prostate cancer and its association with androgen deprivation therapy (ADT).

Design and participants We performed a retrospective cohort study of patients diagnosed with prostate cancer in the Lithuanian male population between 1 January 2003 and 31 December 2012 who were identified through the Lithuanian Cancer registry. All prostate cancer cases were linked to the National Health Insurance Fund database to obtain information regarding the diagnosis of diabetes mellitus and information on prescriptions of antiandrogens and gonadotropin-releasing hormone (GnRH) agonists. Patients with prostate cancer were followed up until the diagnosis of type 2 diabetes, or 31 December 2017, or date of death, whichever came first. Cox proportional hazard models were used to estimate the risk of type 2 diabetes in patients with prostate cancer with or without ADT exposure.

Results 27580 men were diagnosed with prostate cancer, out of whom 14502 (52.6\%) did not receive ADT and 13078 (47.4\%) were treated with ADT. The incidence of type 2 diabetes for all patients with prostate cancer was 7.4/1000 person-years, for men on GnRH agonists 9.0/1000 person-years and 5.8/1000 person-years for men on antiandrogens. There was an increased risk of developing type 2 diabetes comparing ADT users and nonusers ( $\mathrm{HR}=1.49,95 \% \mathrm{Cl} 1.34$ to 1.66).

Conclusion This study showed an increased risk of diabetes in patients with prostate cancer treated with ADT in comparison to ADT-free patient cohort. GnRH agonist users showed higher susceptibility, while the group on antiandrogen monotherapy showed no such increase.

\section{INTRODUCTION}

Prostate cancer is one of the most prevalent malignancies and the second leading cause of cancer-related deaths in men worldwide. ${ }^{1}$ The growth of prostate cancer cells is dependent on androgens; therefore, androgen deprivation therapy (ADT) is the recommended treatment in men with metastatic prostate cancer. ADT is also used in clinically locally advanced prostate cancer in conjunction with
Strengths and limitations of this study

- Large cohort size, population-based design and long observation time (up to 15 years) are strengths of our study.

- Lack of clinical information regarding treatment modality applied for patients in combination with androgen deprivation therapy (ADT), especially information on surgical castration.

- Differences in ADT treatment groups could be influenced by selection bias, as gonadotropin-releasing hormone agonists are used for treatment of metastatic disease, however, differences in ADT treatment groups remain after adjusting to stage of disease.

radiotherapy as either adjuvant or neoadjuvant therapy. ${ }^{2}$

$\mathrm{ADT}$ results in a rapid decrease in serum concentrations of testosterone to castration level by reducing testicular androgens secretion or by inhibiting the androgen receptors. Androgen deprivation can also be achieved with surgery (orchiectomy) or medications (gonadotropin-releasing hormone (GnRH) agonists, GnRH antagonists or oral antiandrogens (AAs)). In addition, complete androgen blockade using combination of GnRH analogues and AAs can also be used in some clinical cases. ${ }^{3}$ If patients with prostate cancer progress to castrate resistance state, it is recommended to continue $\mathrm{ADT}^{4}$

Hypogonadism produced by ADT leads to adverse effects, such as increased risk of cardiovascular disease and metabolic syndrome, anaemia, sexual dysfunction, decreased genital size, gynaecomastia, diminished quality of life, cognitive lesion, hot flushes and reduced bone mineral density. ${ }^{5-8}$ One of the newest long-term effect observed in other studies is ADT increasing insulin 
Table 1 Baseline characteristics of men with prostate cancer by ADT use

\begin{tabular}{|c|c|c|c|c|c|c|}
\hline & All patients & ADT-free cohort & ADT users & AA & GnRH & P value* \\
\hline n (\%) & $27580(100)$ & $14502(52.6)$ & $13078(47.4)$ & $1014(7.8)$ & 12064 (92.2) & \\
\hline Mean follow-up time, years (SE) & $6.74(3.64)$ & $6.54(3.56)$ & $6.97(3.73)$ & $7.12(4.34)$ & $6.95(3.68)$ & \\
\hline $\begin{array}{l}\text { Mean age at diagnosis, } \\
\text { years (SE) }\end{array}$ & $67.81(8.61)$ & $68.71(10.05)$ & $66.81(6.53)$ & $66.10(6.50)$ & $66.87(6.53)$ & $<0.001$ \\
\hline$>75$ & $5812(21.0 \%)$ & $4667(32.2 \%)$ & $1145(8.8 \%)$ & $60(5.9 \%)$ & $1085(9.0 \%)$ & \\
\hline \multicolumn{7}{|l|}{ Stage } \\
\hline I & $1913(6.9 \%)$ & $1380(9.5 \%)$ & $533(4.0 \%)$ & $25(2.5 \%)$ & $508(4.2 \%)$ & $<0.001$ \\
\hline II & $11986(43.5 \%)$ & $6660(45.9 \%)$ & $5326(40.8 \%)$ & $460(45.3 \%)$ & $4866(40.4 \%)$ & \\
\hline
\end{tabular}

*Shows significance of differences between the ADT-free cohort and ADT users.

$A A$, antiandrogen; $A D T$, androgen deprivation therapy; $\mathrm{GnRH}$, gonadotropin-releasing hormone.

resistance and having an impact on type 2 diabetes development. ${ }^{59-12}$

In our large population-based cohort study, we examined the risk of type 2 diabetes in patients with prostate cancer and its association with ADT.

\section{RESEARCH DESIGN AND METHODS \\ Study population}

We performed a retrospective cohort study of patients diagnosed with prostate cancer in the entire Lithuanian male population between 1 January 2003 and 31 December 2012 who were identified through the Lithuanian Cancer registry. The database includes information about the date of diagnosis, age at diagnosis, tumour stage (classified by TNM (Tumour-Node-Metastasis) classification), cause and date of death. Lithuanian data on cancer incidence included Cancer Incidence in Five Continents, a longstanding collaboration between the International Agency for Research on Cancer and the International Association of Cancer Registries, which serves as a unique source of cancer incidence data from high-quality population-based cancer registries around the world. ${ }^{13}$

All prostate cancer cases were linked to the National Health Insurance Fund (NHIF) database in order to obtain information regarding the diagnosis of diabetes mellitus and information on prescriptions of AAs and GnRH agonists. Data linkage between databases was based on the personal identification code, which is unique to each resident in Lithuania. The NHIF database contains demographic data and entries on the primary and secondary healthcare services provided, emergency and hospital admissions and prescriptions of reimbursed medications. Data from the Lithuanian NHIF database encompass about $98 \%$ of inpatient cases and $90 \%$ of outpatient visits (up to $100 \%$ of primary healthcare visits) in Lithuania, covering the entire territory of the country. ${ }^{14}$ Male patients, who in NHIF database were registered with type 2 diabetes (International Classification of Diseases-10 code E11), were considered diabetic. Men who received GnRH agonists or AAs for at least 6 months were defined as ADT users.

Table 2 Incidence of type 2 diabetes per 1000 person-years in patients with prostate cancer by ADT use

\begin{tabular}{lllll}
\hline & Number of patients & Number of events & Person years & Incidence rate \\
\hline All patients & 27580 & 1371 & 185961.74 & 7.4 \\
ADT non-users & 14502 & 570 & 94866.21 & 6.0 \\
ADT users & 13078 & 801 & 91095.53 & 8.8 \\
GnRH agonists users & 12064 & 759 & 87683.91 & 9.0 \\
Antiandrogen users & 1014 & 42 & 3411.62 & 5.8 \\
\hline
\end{tabular}

$\mathrm{ADT}$, androgen deprivation therapy; GnRH, gonadotropin-releasing hormone. 
Table 3 HRs for type 2 diabetes in prostate cancer by use of ADT

\begin{tabular}{lllll}
\hline & HR & $\mathbf{9 5 \%} \mathbf{C l}$ & aHR $^{*}$ & ref. \\
\hline ADT-free cohort & ref. & - & 1.47 & - \\
ADT users & 1.49 & 1.34 to 1.66 & 1.51 & 1.32 to 1.64 \\
GnRH agonists users & 1.53 & 1.38 to 1.71 & 1.02 & 0.74 to 1.39 \\
Antiandrogen users & 1.02 & 0.75 to 1.40 & & 1.69 \\
\hline
\end{tabular}

${ }^{*}$ Adjusted for age and stage.

ADT, androgen deprivation therapy; $\mathrm{GnRH}$, gonadotropin-releasing hormone.

In total between 1 January 2003 and 31 December 2012, 29247 cases of prostate cancer were identified. Patients with prostate cancer with date of prostate cancer diagnosis equal to the date of death (607 cases) and patients with diabetes mellitus diagnosis before prostate cancer diagnosis (1060 cases) were excluded from the analysis. Twenty-seven thousand five hundred and eighty patients with prostate cancer were included in this study.

\section{Statistical analysis}

We analysed risk of diabetes between men on ADT, and patients with prostate cancer not treated with ADT. Identified patients were followed till the date of type 2 diabetes diagnosis, or 31 December 2017, or date of death, whichever came first.

In order to evaluate the risk of developing diabetes among ADT users in cohort of patients with prostate cancer, we calculated exact person-years at risk for each patient.

Cox proportional hazard models were used to estimate HRs and their 95\% CIs to compare risk of diabetes in groups of patients with prostate cancer by ADT exposure. Multivariate adjusted Cox proportional hazards models including age and stage at diagnosis were conducted to estimate the effect of ADT on diabetes risk. Association between duration of GnRH agonists use and diabetes risk was assessed by dividing duration into the following intervals: $0-1,1-2,2-3,3-5$ and more than 5 years. GnRH agonists' users to the duration group were assigned by cumulative exposure.

All statistical analyses were carried out using STATA statistical software (V.15.1).

\section{Patient and public involvement}

This article does not contain any studies with human participants. No patients were involved in this study. Our study was based on retrospective data collected in NHIF database.

\section{RESULTS}

Table 1 presents baseline characteristics of 27580 men who were diagnosed with prostate cancer, out of whom 14502 (52.6\%) did not receive ADT and 13078 (47.4\%) were treated with ADT. The vast majority of patients $(92.2 \%)$ received GnRH agonists and $7.8 \%$ received AAs. There were significant differences between ADT-free cohort and ADT users according to the mean age and stage distribution.

During follow-up period, there were 1371 patients with prostate cancer diagnosed with type 2 diabetes. The incidence of type 2 diabetes for all patients with prostate cancer (ADT users and ADT non-users) was 7.4/1000 person-years. For those who have never used ADT, the incidence was 6.0/1000 person-years. Type 2 diabetes incidence for ADT users was 8.8/1000 person-years, for men on GnRH agonists 9.0/1000 person-years and 5.8/1000 person-years for men on AAs (table 2).

There was a significantly increased risk of developing of type 2 diabetes comparing ADT users with ADT nonusers (HR=1.49, 95\% CI 1.34 to 1.66) (table 3). Adjusted hazards models for patient's age and tumour's stage also showed a statistically higher risk of developing type 2 diabetes $(\mathrm{aHR}=1.47,95 \% \mathrm{CI} 1.32$ to 1.64$)$ in ADT users

\begin{tabular}{|c|c|c|c|c|c|c|}
\hline Years of exposure & Number of events & Number of patients & HR & $95 \% \mathrm{Cl}$ & $\mathrm{aHR}^{*}$ & $95 \% \mathrm{Cl}$ \\
\hline ADT-free cohort & 570 & 14502 & ref. & - & Ref. & - \\
\hline $0-1$ & 369 & 6800 & 1.41 & 1.23 to 1.61 & 1.38 & 1.21 to 1.58 \\
\hline $1-2$ & 139 & 2177 & 1.60 & 1.33 to 1.93 & 1.59 & 1.32 to 1.92 \\
\hline $2-3$ & 105 & 1330 & 1.77 & 1.44 to 2.18 & 1.76 & 1.42 to 2.17 \\
\hline $3-5$ & 96 & 1151 & 1.74 & 1.40 to 2.16 & 1.73 & 1.42 to 2.17 \\
\hline$>5$ & 50 & 606 & 1.58 & 1.18 to 2.11 & 1.57 & 1.17 to 2.10 \\
\hline
\end{tabular}

${ }^{*}$ Adjusted for age and stage.

$\mathrm{ADT}$, androgen deprivation therapy; $\mathrm{GnRH}$, gonadotropin-releasing hormone. 
group. As compared with ADT non-users, the usage of $\mathrm{GnRH}$ agonists was associated with an increased risk of type 2 diabetes ( $\mathrm{HR}=1.53,95 \%$ CI 1.38 to 1.71$)$, however, there was no significant association between oral AA monotherapy and outcome.

Table 4 reports diabetes risk in the group of GnRH agonists users. There were no significant differences in risk by duration of $\mathrm{GnRH}$ agonists exposure duration.

\section{DISCUSSION}

Our patient with prostate cancer cohort study showed increased risk of diabetes in ADT users compared with ADT-free patient cohort. In accordance with other studies, elevated risk was found among GnRH agonist users, while in the AA monotherapy group no such increase was observed.

ADT, which decreases serum testosterone levels by inhibiting testosterone production, has been the first-line treatment for men with locally advanced or metastatic prostate cancer since $1940 .{ }^{15}$ ADT can reduce circulating testosterone levels to castration levels, however, previous studies have shown that low levels of testosterone might decrease lean body mass growth and increase fat deposition, also might cause insulin resistance by reducing insulin sensitivity. ${ }^{16}{ }^{17}$ The association between ADT users in patients with prostate cancer and insulin resistance was identified in Basaria $e t a l \mathrm{~s}^{9}$ study. Patients who received $\mathrm{ADT}$ for at least 12 months had an increased risk of developing insulin resistance and hyperglycaemia. Forty-four per cent of ADT patients had glucose levels in the diabetic range and the duration of ADT was linked to the severity of these metabolic abnormalities. Bosco et $a l \mathrm{~s}^{18}$ meta-analysis results suggested that ADT usage for patients with prostate cancer increased risk of diabetes by $36 \%$. In our study, we also observed that ADT usage increases the risk of diabetes compared with ADT nonusers ( $\mathrm{HR}=1.49,95 \%$ CI 1.34 to 1.66$)$.

Keating et $a \bar{l}$ found that the treatment with GnRH agonists is associated with an increased risk of type 2 diabetes compared with ADT non-users (HR for GnRH agonists vs no ADT $1.44,95 \%$ CI 1.34 to 1.55 ). Crawley et $a l^{2}$ evaluated the risk of type 2 diabetes for the patients treated with GnRH agonists or AAs. They found that GnRH agonists increase the risk of type 2 diabetes. In contrast, management with AAs was not associated with type 2 diabetes. In our study, we showed that the highest risk of diabetes was in GnRH agonists users group $(\mathrm{HR}=1.53,95 \%$ CI 1.38 to 1.71$)$. This data is in line with above mentioned studies.

The duration of ADT is a very important factor when trying to establish the link between type 2 diabetes and ADT. Keating et a $\tilde{\varphi}$ showed increased risk of type 2 diabetes for patients on GnRH agonists, however, this study had a relatively short duration (up to 25 months). To our knowledge, Crawley and colleagues were the first that evaluted different types of ADT and the effect of treatment duration. They examined the risk of type 2 diabetes with up to 10 years of exposure. In their study, they revealed that patients on GnRH agonists during the first 3 years (2-2.5 years of exposure $\mathrm{HR}=1.68,95 \%$ CI 1.40 to 2.02 ) had the highest risk of developing type 2 diabetes. ${ }^{12}$ Similarly, we showed that the highest incidence of diabetes was in the 3-year exposure group ( $\mathrm{HR}=1.77,95 \%$ CI 1.44 to 2.18), however, the risk was also significantly elevated in other categories.

Intermittent $\mathrm{ADT}$ treatment was suggested as an alternative treatment to continuous ADT with possibly fewer complications and better quality of life. ${ }^{19}$ Rezaei et $a t^{20}$ study's results showed that in short-term treatment with intermittent ADT there was no difference in fasting blood glucose, which suggests lower risks of diabetes mellitus in this group of patients. Thus, difference in diabetes risk increase between non-users and ADT users could be mitigated by the proportion of intermittent ADT user in our cohort, whom we could not identify from our database. However, according to general used prostate cancer treatment guidelines, intermittent ADT could be applicable only for very small and well-informed fraction of patients with prostate cancer. ${ }^{21}$ Therefore, we consider that this should not influence the final results of our study.

Large cohort size, population-based design and long observation time (up to 15 years) are strengths of our study. Main limitation of our study is lack of clinical information regarding treatment modality, applied for patients in combination with ADT, especially information on surgical castration. This type of ADT is not common in clinical practice, therefore inclusion of those cases in non-ADT patients group has no substantial effect on diabetes risk evaluation. Another limitation is that differences in ADT treatment groups could be influenced by selection bias, as GnRH agonists are used for treatment of metastatic disease, however, differences in ADT treatment groups remain after adjusting to stage of disease.

\section{CONCLUSION}

This study showed that there is increased risk of diabetes in patients with prostate cancer treated with ADT in comparison with ADT-free patient cohort. GnRH agonist users showed higher susceptibility while the group on AA monotherapy showed no such increase.

Twitter Ausvydas Patasius @ausvydasp

Contributors MD, AP and GS contributed to conceptualisation; AP, MK, VU, GS contributed to planning; GS contributed to data curation; AP and GS contributed to formal analysis, methodology; GS contributed to project administration, resources, supervision; MD contributed to writing-original draft; MD, AP, MK, VU and GS contributed to writing-review \& editing; MK, VU, GS contributed to conception and design.

Funding The authors have not declared a specific grant for this research from any funding agency in the public, commercial or not-for-profit sectors.

Competing interests None declared.

Patient and public involvement Patients and/or the public were not involved in the design, or conduct, or reporting, or dissemination plans of this research.

Patient consent for publication Obtained. 
Ethics approval This research was approved by Vilnius regional bioethics committee (Nr. 158200-16-879-388). Bioethics committee waived off informed consent.

Provenance and peer review Not commissioned; externally peer reviewed.

Data availability statement Data are available upon reasonable request.

Open access This is an open access article distributed in accordance with the Creative Commons Attribution Non Commercial (CC BY-NC 4.0) license, which permits others to distribute, remix, adapt, build upon this work non-commercially, and license their derivative works on different terms, provided the original work is properly cited, appropriate credit is given, any changes made indicated, and the use is non-commercial. See: http://creativecommons.org/licenses/by-nc/4.0/.

\section{ORCID iDs}

Mingaile Drevinskaite http://orcid.org/0000-0002-4778-3749

Ausvydas Patasius http://orcid.org/0000-0003-3874-2723

Giedre Smailyte http://orcid.org/0000-0001-8365-543X

\section{REFERENCES}

1 Siegel RL, Miller KD, Jemal A. Cancer statistics, 2019. CA Cancer J Clin 2019;69:7-34.

2 Parker C, Gillessen S, Heidenreich A, et al. Cancer of the prostate: ESMO clinical practice guidelines for diagnosis, treatment and follow-up. Annals of Oncology 2015;26:v69-77.

3 Jhan J-H, Yeh $\mathrm{H}-\mathrm{C}$, Chang $\mathrm{Y}-\mathrm{H}$, et al. New-Onset diabetes after androgen-deprivation therapy for prostate cancer: a nationwide propensity score-matched four-year longitudinal cohort study. $J$ Diabetes Complications 2018;32:688-92.

4 Lycken M, Garmo H, Adolfsson J, et al. Patterns of androgen deprivation therapies among men diagnosed with localised prostate cancer: a population-based study. Eur J Cancer 2014;50:1789-98.

5 Keating NL, O'Malley AJ, Smith MR. Diabetes and cardiovascular disease during androgen deprivation therapy for prostate cancer. JCO 2006;24:4448-56.

6 Choo R, Chander S, Danjoux C, et al. How are hemoglobin levels affected by androgen deprivation in non-metastatic prostate cancer patients? Can J Urol 2005;12:2547-52.

7 Nguyen PL, Alibhai SMH, Basaria S, et al. Adverse effects of androgen deprivation therapy and strategies to mitigate them. Eur Urol 2015;67:825-36.
8 Rhee $\mathrm{H}$, Gunter JH, Heathcote P, et al. Adverse effects of androgendeprivation therapy in prostate cancer and their management. BJU Int 2015;115:3-13.

9 Basaria S, Muller DC, Carducci MA, et al. Hyperglycemia and insulin resistance in men with prostate carcinoma who receive androgendeprivation therapy. Cancer 2006;106:581-8.

10 Keating NL, O'Malley AJ, Freedland SJ, et al. Diabetes and cardiovascular disease during androgen deprivation therapy: observational study of veterans with prostate cancer. JNCl Journal of the National Cancer Institute 2010;102:39-46.

11 Lage MJ, Barber BL, Markus RA. Association between androgendeprivation therapy and incidence of diabetes among males with prostate cancer. Urology 2007;70:1104-8.

12 Crawley D, Garmo H, Rudman S, et al. Association between duration and type of androgen deprivation therapy and risk of diabetes in men with prostate cancer. Int. J. Cancer 2016;139:2698-704.

13 Bray F, Ferlay J, Laversanne M, et al. Cancer incidence in five continents: inclusion criteria, highlights from volume $\mathrm{X}$ and the global status of cancer registration. Int J Cancer 2015;137:2060-71.

14 Navickas R, Visockiené Ž., Puronaitė R, et al. Prevalence and structure of multiple chronic conditions in Lithuanian population and the distribution of the associated healthcare resources. Eur J Intern Med 2015;26:160-8.

15 Huggins C, Stevens RE, Hodges CV. Studies on prostatic cancer: II. The effects of castration on advanced carcinoma of the prostate gland. Arch Surg 1941;43:209-23.

16 Smith MR. Changes in fat and lean body mass during androgendeprivation therapy for prostate cancer. Urology 2004;63:742-5.

17 Smith MR, Lee H, Nathan DM. Insulin sensitivity during combined androgen blockade for prostate cancer. J Clin Endocrinol Metab 2006;91:1305-8.

18 Bosco C, Crawley D, Adolfsson J, et al. Quantifying the evidence for the risk of metabolic syndrome and its components following androgen deprivation therapy for prostate cancer: a meta-analysis. PLoS One 2015;10:e0117344.

19 Tunn UW, Canepa G, Kochanowsky A, et al. Testosterone recovery in the off-treatment time in prostate cancer patients undergoing intermittent androgen deprivation therapy. Prostate Cancer Prostatic Dis 2012;15:296-302.

20 Rezaei MM, Rezaei MM, Ghoreifi A, et al. Metabolic syndrome in patients with prostate cancer undergoing intermittent androgendeprivation therapy. Can Urol Assoc J 2016;10:300-5.

21 Hussain M, Tangen CM, Berry DL, et al. Intermittent versus continuous androgen deprivation in prostate cancer. New England Journal of Medicine 2013;368:1314-25. 